Journal of Engineering and Applied Sciences 14 (Special Issue 3): 6110-6113, 2019

ISSN: $1816-949 \mathrm{X}$

(C) Medwell Journals, 2019

\title{
Performance Assessment of Steel Fibre Reinforced Self-Compacting Concrete (SCFRC) Panel with Ribbed Profile
}

\author{
${ }^{1}$ Hazrina Ahmad, ${ }^{2}$ M.H. Mohd Hisbany, ${ }^{2}$ B. Ezatul Yasmin and ${ }^{3}$ M.F. Nurulain Hanida \\ ${ }^{1}$ Faculty of Civil Engineering, 13500 Permatang Pauh, Malaysia \\ ${ }^{2}$ Faculty of Civil Engineering, 40450 Shah Alam, Malaysia \\ ${ }^{3}$ Faculty of Engineering and Science, Universiti Tunku Abdul Rahman, 43000 Kajang, Selangor
}

\begin{abstract}
This study presents a part of a research project conducted to develop a Steel Fibre Reinforced Self-Compacting Concrete (SCFRC) precast ribbed slab panel for domestic application. The research project aims to fully utilize the potentials of the flowability of the Self-compacting Concrete (SCC) mix with steel fibres to replace conventional reinforcements. Four square ribbed slab samples with the dimension of $1.2 \times 1.2 \mathrm{~m}$ were constructed varying in terms of the flange thickness $(100$ and $120 \mathrm{~mm})$ and steel fibre provision area (fully and partially reinforced). The volume of steel fibres incorporated in the SCFRC mix was $80 \mathrm{~kg} / \mathrm{m}^{3}$, equivalent to $1 \%$ volume fraction. The slab samples were subjected to a point load at a centre point load to assess their flexural and post-cracking behaviour. Generally, the analysis of the experimental results displayed that steel fibres incorporation had effectively contribute to the load bearing capacity of the ribbed slab panels. The highest load bearing capacity was achieved by Sample S2-120 with the ultimate load of $158.37 \mathrm{kN}$, followed by S2-100 $(112.32 \mathrm{kN})$. With regards to the flange thicknesses, results presented shows that higher thickness led to higher load bearing capacity with lesser deflection. However, in terms of the post-cracking behaviour, leads to steeper load-deflection curves causing the samples to experience more severe cracking as well as spalling of the concrete surface. In terms of the steel provision area, ribbed slab samples that were fully reinforced with steel fibres showed better flexural behaviour with higher load bearing capacity as well as lower deflection in comparison to the partially reinforced samples. Visual observation of the samples also showed that the partially reinforced Samples (S3) experienced more severe failure than fully reinforced Samples (S2). Overall, based on the results, it can be concluded that fully steel fibre reinforced samples with higher flange thickness displayed a promising potential to effectively replace conventional reinforcements.
\end{abstract}

Key words: Self-compacting concrete, steel fibres, ribbed slab, reinforcements, load bearing capacity, cracking

\section{INTRODUCTION}

Self-Compacting Concrete (SCC) has the ability to be properly poured in place to fill the formwork by means of its own weight without the needs of any vibration. The rheological property of SCC allows the material to be applied in complex shaped elements and structures with congested reinforcements (Domone, 2007; Ferrara and Meda, 2006; Fritih et al., 2013; Khaloo et al., 2014; Okamura and Ouchi, 2003). The flow ability of SCC offers advantages to the construction process, thus, minimizing the need of skilled workers. Furthermore, it leads to a reduction of costs as well as time saving (Pajak and Ponikiewski, 2013). Steel Fibre Reinforced Self-Compacting Concrete (SCFRC) on the other hand combines the benefits of the (SCC) technology with the advantages derived from the fibre addition to the SCC matrix. SCFRC combines the advantages of SCC at fresh state with the enhancement of the material at hardened state with addition of the steel fibres (Grunewald, 2004). Amongst the properties improved by the steel fibre inclusion are the tensile strength, ductility, toughness, energy absorption capacity (Grunewald and Walraven, 2009; Khaloo and Afshari, 2005) fracture toughness (Akcay and Tasdemir, 2012; Domone, 2007; El-Dieb, 2009) as well as cracking resistance (Aslani et al., 2014). Owing to these positive effects of steel fibres in enhancing the concrete's hardened properties, especially by its contribution against crack propagation and enhancement in ductility, this current research is moving towards investigating the function of the fibres as the reinforcing material the steel fibres can function as a reinforcing material to partially or totally replace conventional reinforcements in concrete structures (Michels et al., 2012). This study aims to evaluate the flexural performance of SCFRC panels with ribbed profiles.

\section{MATERIALS AND METHODS}

Mix design: Grade 30 Self-Compacting Concrete (SCC) was used for the fabrication of all slab samples with the composition shown in Table 1. The mix was produced in

Corresponding Author: Hazrina Ahmad, Faculty of Civil Engineering, 13500 Permatang Pauh, Malaysia 
Table 1: SCC Mix composition

\begin{tabular}{|c|c|c|c|c|c|c|}
\hline $\begin{array}{l}\text { Cement } \\
\text { CEM I 42.5R }\end{array}$ & $\begin{array}{l}\text { Pulverized fly ash } \\
\text { (Class F) }\end{array}$ & $\begin{array}{l}\text { Coarse aggregate } \\
(10 \mathrm{~mm})\end{array}$ & Fine aggregate & Water & $w / c$ & Steel fibre content \\
\hline $315 \mathrm{~kg} / \mathrm{m}^{3}$ & $105 \mathrm{~kg} / \mathrm{m}^{3}$ & $830 \mathrm{~kg} / \mathrm{m}^{3}$ & $865 \mathrm{~kg} / \mathrm{m}^{3}$ & $185 \mathrm{~kg} / \mathrm{m}^{3}$ & 0.44 & $80 \mathrm{~kg} / \mathrm{m}^{3}$ \\
\hline
\end{tabular}

Table 2: Sample details

\begin{tabular}{lll}
\hline Designation & Flange thickness $(\mathrm{mm})$ & Reinforcement \\
S2-100 & 100 & Fully steel fibre reinforced \\
S3-100 & & Partially steel fibre reinforced with BRC \\
S2-120 & 200 & Fully steel fibre reinforced \\
S3-120 & & Partially steel fibre reinforced with BRC \\
\hline
\end{tabular}
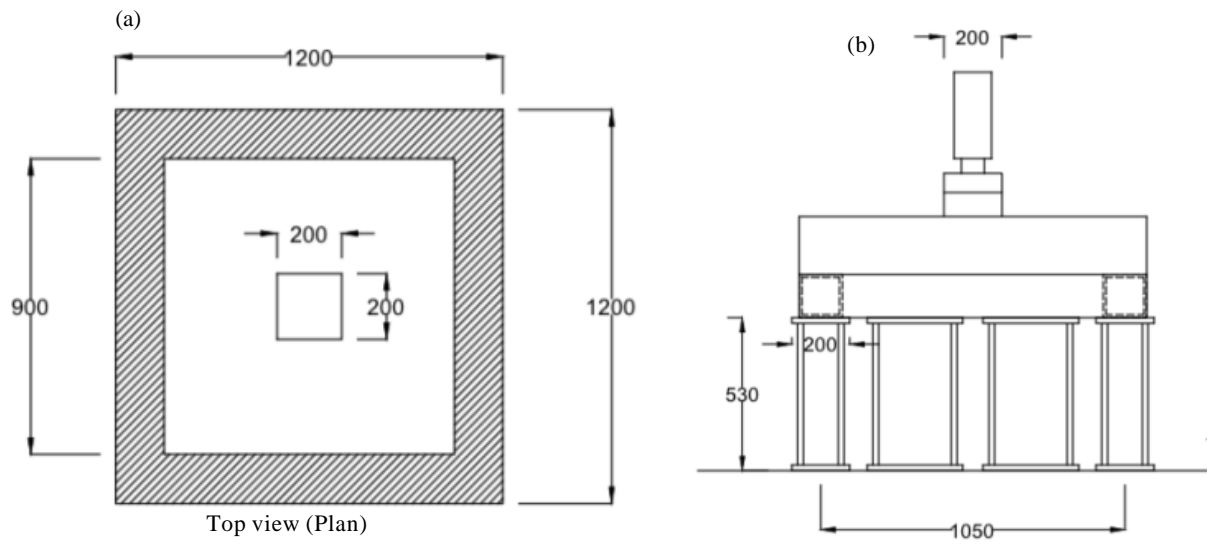

Fig. 1: a, b) Experimental setup (top and side view)

the plant and delivered to the laboratory. Hooked end steel fibres of $35 \mathrm{~mm}$ length (Stahlcon HE 0.55/35) were manually added to the truck mixer at the end of the mixing process. This type of steel fibre was chosen to enhance the anchorage between the fibres and the concrete matrix. Hooked end fibre produces greater friction and pull-out forces between the fibres and the aggregates in the matrix as compared to straight fibers (Grunewald, 2004) as well as higher toughness and residual strength (Pajak and Ponikiewski, 2013; Shah and Ribakov, 2011). Similar fibre dosage of $80 \mathrm{~kg} / \mathrm{m}^{3}(1 \%)$ was used for all slab samples considering the optimum volume fraction from preliminary testing and previous research by Sarbini et al. (2012). The fibres are glued in bundles to facilitate the fibre distribution during concrete mixing and avoid the fibre balling effect (Rahman et al., 2012; Shah and Ribakov, 2011; Tazaly, 2012). Detail results on the mechanical properties (compressive, tensile splitting, flexural strength) is reported elsewhere (Hazrina et al., 2018).

The 4 square ribbed slab samples with the dimension of $1.2 \times 1.2 \mathrm{~m}$ with the total slab thickness of $0.2 \mathrm{~m}$ were cast in the Heavy Structures Laboratory, Universiti Teknologi MARA. Since, the mix used for the fabrication of the samples was classified as a self-compacting concrete mix no vibration was applied during casting of the samples. The details of the sample were as listed in Table 2 .
Experimental setup: Figure 1 shows the experimental setup for slab loading process. The $1.2 \mathrm{~m}$ square slab samples were simply supported on its four sides and loaded on a surface of $200 \times 200 \mathrm{~mm}$ in the slab centre. A total of 5 linear displacement transducers were located at the bottom of the slab to measure deflection. One of the transducers was located at the centre of the slab while the other for were placed at the symmetry axes to form a cross. The loading of the samples was carried out by displacement control at a rate of $0.01 \mathrm{~mm} / \mathrm{sec}$.

\section{RESULTS AND DISCUSSION}

Crack pattern and failure mode: The crack pattern of all four slab samples that was subjected to the concentrated load exhibited radial cracks appearing from the middle loading point extending to the edges of the slab. Even with the presence of the rib profile, crack patterns that resembled the yield line theory were observed in the tested samples. In general, based on the visual observation, three main cracks were formed with multiple minor cracks. Crack occurrence of the S3 Sample showed more severe and larger cracks accompanied by obvious spalling at the bottom of the sample exhibiting the disintegration of the matrix from the structure. The crack pattern may be attributed by the greater deflection experienced by the S3 slabs in comparison to the S2 slabs. 


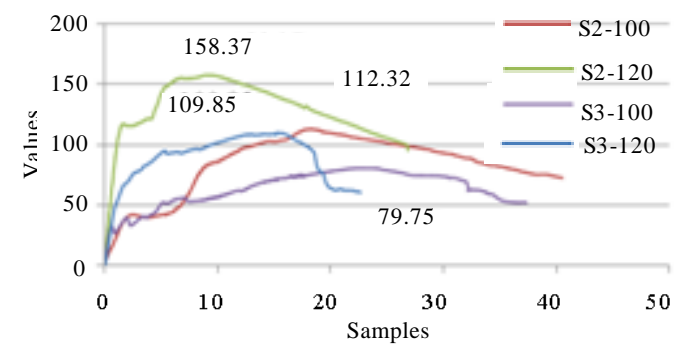

Fig. 2: Load versus deflection curves of all samples

S2 slabs that were fully reinforced with steel fibres were observed to be better in sustaining the slab from cracks exhibiting better post-cracking behaviour in comparison to S3 slabs. Close observation of the crack mouth showed the bridging of the cracks by the steel fibres.

Load versus deflection: The load-deflection curves as shown on Fig. 2 for all samples exhibit deflectionhardening behaviour upon experiencing the first crack. The graph continued to gradually increase until the ultimate load was achieved. Beyond the ultimate load, the graph progressively descends as the deflection continues further. This proved the strong interaction between the steel fibres and the SCC matrix that effectively transferred the stresses in the structure even after the crack occurrence. The steel fibres in the samples effectively hold the hardened SCC matrix together even after extensive cracking under concentrated loading demonstrating good post-cracking ductility (Narwal et al., 2013). Only Sample S3-120 showed some drastic descend of the curve after the achievement of the ultimate load. This might be due to the fact that the even though sample S3-120 had higher flange thickness, resulting in the sample with lesser steel fibre provision area (shallower rib section). This had caused the sample to drastically lose its strength upon reaching its ultimate load due to the loss of bonding between the steel fibres.

Effect of steel fibre provision area: From the graphs, it can be observed that higher ultimate load was achieved by S2 Samples that was fully reinforced with steel fibres. This shows that the provision of steel fibres for the whole section, tensile and compressive zone contributed to the ultimate strength of the section. The highest ultimate load was achieved by Sample S2-120 (158.37 kN) and followed by $\mathrm{S} 2-100(112.32 \mathrm{kN})$ for flange thicknesses of 120 and $100 \mathrm{~mm}$, respectively. The ultimate strength of Samples S3-120 and S2-100 showed only a slight difference of approximately $2 \%$ while Sample S3-100 showed lower value.

Effect of flange thickness: Samples with higher flange thickness $(120 \mathrm{~mm})$ experienced first crack at higher
Table 3: Ultimate load and the corresponding deflection

\begin{tabular}{lcc}
\hline Samples & Ultimate load $(\mathrm{kN})$ & Deflection $(\mathrm{mm})$ \\
\hline S2-100 & 112.32 & 18.27 \\
S2-120 & 158.37 & 09.13 \\
S3-100 & 079.75 & 23.09 \\
S3-120 & 109.85 & 15.32 \\
\hline
\end{tabular}

ultimate load in comparison to samples with $100 \mathrm{~mm}$ flange thickness. This proved the contribution of the slab geometry to the crack occurrence of the slab samples. The ultimate load was achieved at later stage at higher deflection for samples with lesser flange thickness $(100 \mathrm{~mm})$ in both S2 and S3 Samples. This might be due to the higher tensile zone of these samples that allows the slab to experience higher deflection before reaching the ultimate strength. Significant difference in the ultimate load is as the result of the variation in the flange thickness that influenced the fibre content in the structure that contributes to the ductile behaviour of the slab. Lower values of ultimate loads were observed for the S3 Samples that was partially reinforced with steel fibres in the ribs and $\mathrm{BRC}$ in the flange.

Table 3 showed the maximum deflection that corresponds to the ultimate load of each slab sample measured by the LVDT located at the middle rib soffit. Slab Samples S2 showed lesser deflection in comparison to the S3 Samples exhibiting the ability of the sample fully reinforced with steel fibres to sustain loads with minimal deformation. Samples with higher flange thickness also showed the same trend by experiencing lower deflection value.

\section{CONCLUSION}

Generally, the analysis of the experimental results displayed that steel fibres incorporation had effectively contribute to the load bearing capacity of the ribbed slab panels. The highest load bearing capacity was achieved by Sample S2-120 with the ultimate load of $158.37 \mathrm{kN}$, followed by $\mathrm{S} 2-100(112.32 \mathrm{kN})$. With regards to the flange thicknesses, results presented shows that higher thickness led to higher load bearing capacity with lesser deflection. However, in terms of the post-cracking behaviour, leads to steeper load-deflection curves causing the samples to experience more severe cracking as well as spalling of the concrete surface. In terms of the steel provision area, ribbed slab samples that were fully reinforced with steel fibres showed better flexural behaviour with higher load bearing capacity as well as lower deflection in comparison to the partially reinforced samples. Visual observation of the samples also showed that the partially reinforced Samples (S3) experienced more severe failure than fully reinforced Samples (S2). Overall, based on the results, it can be concluded that fully steel 
fibre reinforced samples with higher flange thickness displayed a promising potential to effectively replace conventional reinforcements.

\section{ACKNOWLEDGEMENTS}

Special thanks to the laboratory staffs of the Faculty of Civil Engineering, UiTM, Malaysia for their technical support and the Institute of Research Management and Innovation (IRMI) for their assistance in managing the research process. This study was funded by the e-Science Fund (06-01-01-SF0835) from the Ministry of Science, Technology and Innovation (MOSTI) of Malaysia.

\section{REFERENCES}

Akcay, B. and M.A. Tasdemir, 2012. Mechanical behaviour and fibre dispersion of hybrid steel fibre reinforced self-compacting concrete. Constr. Build. Mater., 28: 287-293.

Aslani, F., S. Nejadi and B. Samali, 2014. Short term bond shear stress and cracking control of reinforced self-compacting concrete one way slabs under flexural loading. Comput. Concr., 13: 709-737.

Domone, P.L., 2007. A review of the hardened mechanical properties of self-compacting concrete. Cem. Concr. Composites, 29: 1-12.

El-Dieb, A.S., 2009. Mechanical, durability and microstructural characteristics of ultra-high-strength self-compacting concrete incorporating steel fibers. Mater. Des., 30: 4286-4292.

Ferrara, L. and A. Meda, 2006. Relationships between fibre distribution, workability and the mechanical properties of SFRC applied to precast roof elements. Mater. Struct., 39: 411-420.

Fritih, Y., T. Vidal, A. Turatsinze and G. Pons, 2013. Flexural and shear behavior of steel fiber reinforced SCC beams. KSCE. J. Civil Eng., 17: 1383-1393.

Grunewald, S. and J.C. Walraven, 2009. Transporting fibres as reinforcement in self-compacting concrete. Heron, 54: 101-1026.

Grunewald, S., 2004. Performance-based design of self-compacting fibre reinforced concrete. Ph.D Thesis, Delft University of Technology, Delft, Netherlands.
Hazrina, A., M.M. Hisbany, A.B. Afidah, H.S. Hawa and A.R. Fadhillah, 2018. Effects of steel fibre addition on the mechanical properties of steel fibre reinforced self-compacting concrete (Sccfibre). IOP. Conf. Ser. Mater. Sci. Eng., 431: 1-10.

Khaloo, A., E.M. Raisi, P. Hosseini and H. Tahsiri, 2014. Mechanical performance of self-compacting concrete reinforced with steel fibers. Constr. Build. Mater., 51: 179-186.

Khaloo, A.R. and M. Afshari, 2005. Flexural behaviour of small steel fibre reinforced concrete slabs. Cement Concr. Compos., 27: 141-149.

Michels, J., D. Waldmann, S. Maas and A. Zurbes, 2012. Steel fibers as only reinforcement for flat slab construction-Experimental investigation and design. Constr. Build. Mater., 26: 145-155.

Narwal, J., A. Goel, D. Sharma, D.R. Kapoor and B. Singh, 2013. An experimental investigation on structural performance of steel fibre reinforced concrete beam. Intl. J. Eng. Adv. Technol., 2: 301-304.

Okamura, H. and M. Ouchi, 2003. Self-compacting concrete. J. Adv. Concr. Technol., 1: 5-15.

Pajak, M. and T. Ponikiewski, 2013. Flexural behavior of self-compacting concrete reinforced with different types of steel fibers. Constr. Build. Mater., 47: 397-408.

Rahman, N.A., S.H. Hamzah and A. Abdulrazzaq, 2012. Effectiveness of stefib in composite structural member. J. Eng. Sci. Technol., 7: 552-562.

Sarbini, N.N., I.S. Ibrahim and A.A. Saim, 2012. Assessment on the mechanical performance of steel fibre reinforced concrete using fibres geometrical factor. Proceedings of 8th RILEM International Symposium on Fibre Reinforced Concrete: Challenges and Opportunities (BEFIB 2012), September 19-21, 2012, Guimaraes, Portugal, pp: 19-21.

Shah, A.A. and Y. Ribakov, 2011. Recent trends in steel fibered high-strength concrete. Mater. Des., 32: $4122-4151$.

Tazaly, Z., 2012. Punching shear capacity of fibre reinforced concrete slabs with conventional reinforcement: Computational analysis of punching models. MSc Thesis, KTH Royal Institute of Technology, Stockholm, Sweden. 